CASE REPORT

\title{
A New Case of a Primary Hydatid Cyst of Chest Wall
}

\author{
Harmouchi $\mathrm{H}^{1^{*}}$, Belliraj $\mathrm{L}^{1}$, Ammor FZ ${ }^{1}$, Issoufou $\mathrm{I}^{1}$, Lakranbi $\mathrm{M}^{1,2}$, Ouadnouni $\mathrm{Y}^{1,2}$ and Smahi $\mathrm{M}^{1,2}$ \\ ${ }^{1}$ Department of Thoracic Surgery, CHU Hassan II of Fez-Morocco, Morocco \\ ${ }^{2}$ Faculty of Medicine and Pharmacy, Sidi Mohamed Ben Abdallah University, Fez-Morocco
}

*Corresponding author: Harmouchi H, Department of Thoracic Surgery, CHU Hassan II of Fez-Morocco, BP: 30000, Morocco, Tel: 00212664153156, E-mail: harmouchi.hicham@gmail.com

Citation: Harmouchi H, Belliraj L, Ammor FZ, Issoufou I, Lakranbi M, et al. (2018) A New Case of a Primary Hydatid Cyst of Chest Wall. Saj Case Rep 5: 410

Article history: Received: 24 October 2018, Accepted: 29 November 2018, Published: 30 November 2018

\begin{abstract}
Hydatidosis, which is a parasitosis caused by echinococcus granulosus, remains an endemic pathology in Morocco. The liver and the lung present the preferential localization of this pathology, however the localization at the chest wall is extremely rare. We report the case of an elderly woman who consults for a tumefaction of the right anterior chest wall. Ultrasound of soft tissues has objectified a well-defined cystic formation below the clavicle. However, the Radiological investigations especially for the liver and lungs was negative.
\end{abstract}

Keywords: Hydatid Cyst; Chest Wall; Surgery

\section{Case report}

This is a 70-year-old patient who lives in a rural area, with no notable pathological history, who has had a chest wall swelling gradually increasing in size over the last year. The clinical examination found a mass of the right anterior chest wall under the clavicle, soft renitent, not painful on palpation. The patient initially benefited from an ultrasound of the soft tissue which speaks of a well-defined cystic formation of $4^{\star} 2 \mathrm{~cm}$, homogeneous, oval, in the subcutaneous localization (Figure 1). In dorsal decubitus, under a general anesthesia, the patient underwent surgery for her mass, which found a parietal hydatid cyst (Figure 2). The anatomopathological study of the operative specimen (Figure 3) was also in favor of a hydatid cyst. As part of the additional management, the patient had a thoracic CT and a hepatic ultrasonography that did not aim for hydatid localization in the liver or the lung. The follow-up was 1 year without any marked recurrence.

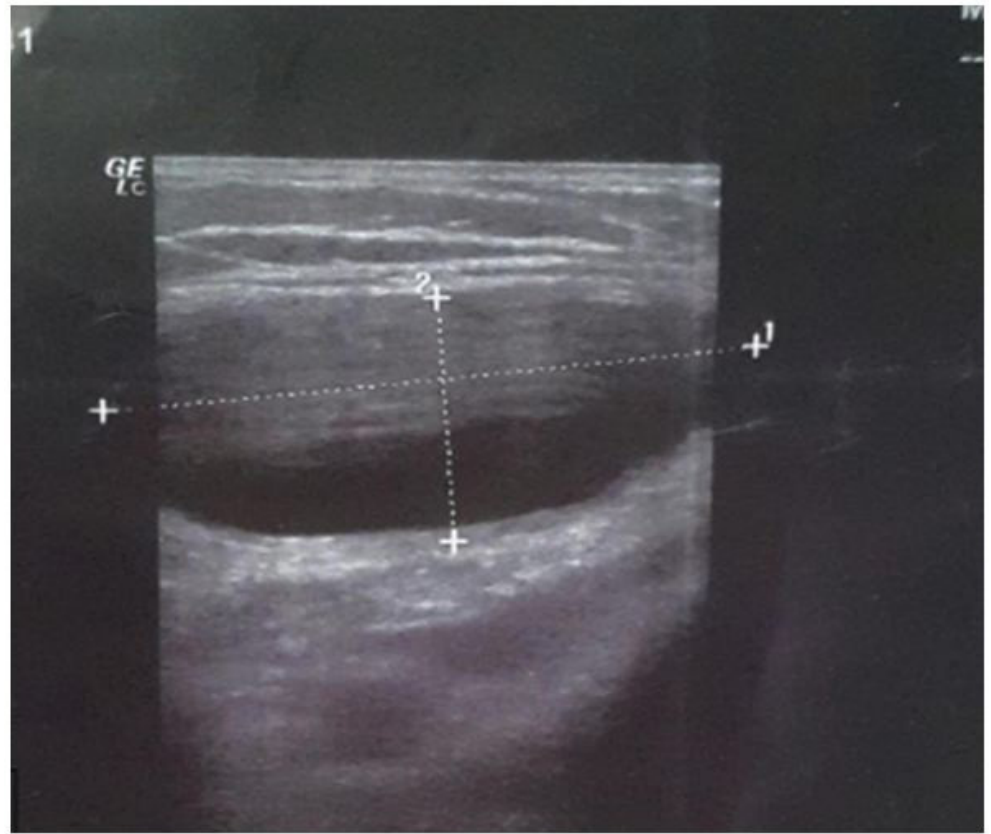

Figure 1: Ultrasound of the soft tissues showing a well-defined homogeneous cystic formation, of oval shape, in the subcutaneous localization 


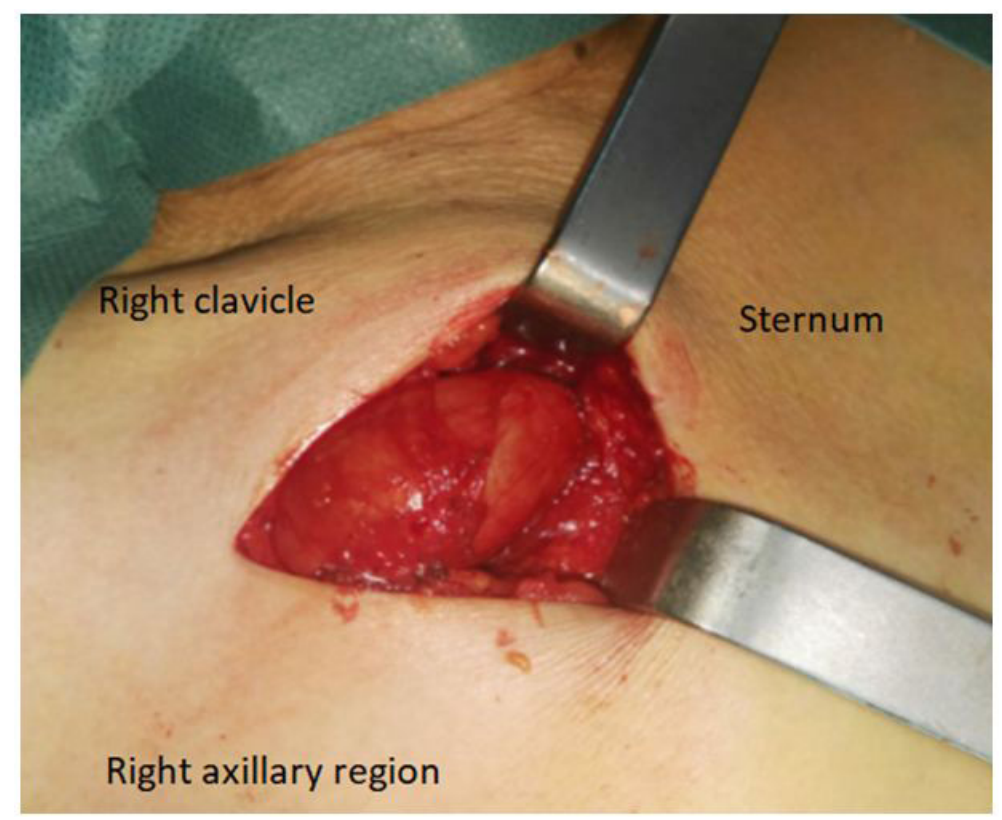

Figure 2: Surgical act objectifying a hydatid cyst of the chest wall

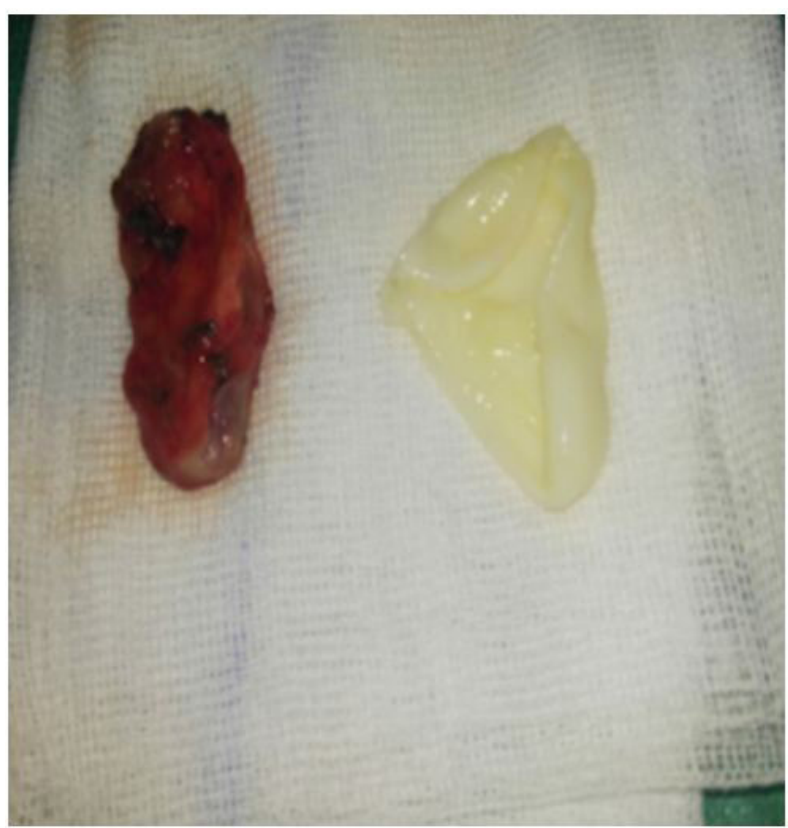

Figure 3: surgical specimen showed the hydatid cyst

\section{Discussion}

The hydatid cyst is a benign parasitic pathology that is caused by echinococcus granulosis, and which present an endemic disease in some regions of the world, particularly in many Mediterranean countries like Morocco [1,2]. It is caused to the close associations among sheep, dogs and humans. Humans are the accidental host and contract the infection accidently. In adults the lung is the second most common organ for hydatid disease after the liver [3]. Hydatid disease of the chest wall is extremely rare even in endemic areas. In literature, the primary hydatid cyst of the chest wall was reported only in eight publications [4]. The mechanism of primary hydatid disease of the chest wall may be explained by passage of the embryo through the duodenal wall into either the portal vein or the periduedonal and perigastric lymphatics. Periduodenal and perigastric lymphatic channels connect with the thoraco-mediastinal lymphatic and the thoracic duct [5]. This mechanism may explain the development of primary chest wall hydatid disease in the absence of pulmonary or hepatic cysts [6]. In our case, the decision was made to operate the patient according to the ultrasound of the soft parts, since the lesion was cystic, well limited, leading to benign pathology like a lipoma. The hydatid serology, when it is positive, allows to evoke the diagnosis. The thoracic CT, in addition to the demonstration of a lesion with fluid density at the level of the thoracic wall, it allows to look for other localization especially at the level of the lungs and liver. The rupture of pulmonary hydatid cysts into the pleural space, either spontaneously or during the operation, is the most common cause of pleural hydatidosis or chest wall hydatidosis [2]. However, in this case, the patient has never been operated for a hydatid cyst. So, we are in front a primary hydatid cyst of chest wall which is an unusual location for primary echinococcus 
disease. The treatment is based on a surgical intervention by excision of the hydatid cyst of chest wall. The anthelminthic treatment is indicated in hydatid cyst ruptured in soft tissue before excision, or deep-locating parietal hydatid cyst broken up in the pleural cavity essentially the costal hydatid cyst.

\section{Conclusion}

Even that the localization in chest wall is rare, it is important to evoke the diagnosis of hydatid cyst in front of masses of the chest wall, especially in countries where hydatidosis is endemic, and especially when consistency of the lesion is soft.

\section{References}

1. Oguzkaya F, Akcali Y, Kahraman C, Emirogullari N, Bilgin M, et al. (1997) Unusually located hydatid cysts: intrathoracic but extrapulmonary. Ann Thorac Surg 64: $334-7$

2. Ozdemir N, Akal M, Kutlay H, Yavuzer S (1994) Chest wall echinococcosis. Chest 105: 1277-9.

3. Aletros H, Symbos PN (2000) Hydatid disease of the lung. In: General thoracic surgery (5th edn). Philadelphia, PA, Lippincott: 1113-22.

4. Abdulwahid MS, Dilshad MA, Fahmi HK, Rawand AE, Hunar AH, et al. (2017) Primary chest wall Hydatid cyst: Review of literature with report of a new case. Int J Surg Case Rep 41: 404-6.

5. Sarsam A (1971) Surgery of pulmonary hydatid cysts. Review of 155 cases. J Thoracvasc Surg 62: 663-8.

6. Alper F, Dalokay K, Tuba C, Ahmet H (2007) Primary Hydatid Disease of the Chest Wall. Ann Thorac Cardiovasc Surg 13: 203-5. 